\title{
Hailey-Hailey Disease: A Case Study Report with Review of Literature
}

\author{
Dr. Shweta ${ }^{1}$, Dr. Vijetha Rai ${ }^{2}$, Dr. Kuladeepa Ananda Vaidya ${ }^{3}$, \& Dr. Sukesh ${ }^{4}$ \\ ${ }^{1}$ Post graduate student, Department of Pathology, Srinivas Institute of Medical Science and \\ Research Centre, Mukka, Mangalore-575021 \\ ${ }^{2}$ Assistant professor, Department of Dermatology, Srinivas Institute of Medical Science and \\ Research Centre, Mukka, Mangalore-575021 \\ ${ }^{3}$ Associate professor, Department of Pathology, Srinivas Institute of Medical Science and \\ Research Centre, Mukka, Mangalore-575021 \\ ${ }^{4}$ Professor and HOD, Department of Pathology, Srinivas Institute of Medical Science and \\ Research Centre, Mukka, Mangalore-575021 \\ E-Mail : shweta992@gmail.com
}

Type of the Paper: Medical Case Report.

Type of Review: Peer Reviewed.

Indexed In: OpenAIRE.

DOI: http://dx.doi.org/10.5281/zenodo.1214176.

Google Scholar Citation: IJHSP

\section{How to Cite this Paper:}

Shweta., Rai Vijetha, Vaidya Kuladeepa Ananda., \& Sukesh. (2018). Hailey-Hailey Disease: A Case Study Report with Review of Literature. International Journal of Health Sciences and Pharmacy (IJHSP), 2(1), 13-17.

DOI: http://dx.doi.org/10.5281/zenodo.1214176.

International Journal of Health Sciences and Pharmacy (IJHSP)

A Refereed International Journal of Srinivas University, India.

(C) With Authors.

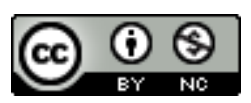

This work is licensed under a Creative Commons Attribution-Non Commercial 4.0 International License subject to proper citation to the publication source of the work.

Disclaimer: The scholarly papers as reviewed and published by the Srinivas Publications (S.P.), India are the views and opinions of their respective authors and are not the views or opinions of the SP. The SP disclaims of any harm or loss caused due to the published content to any party. 


\title{
Hailey-Hailey Disease: A Case Study Report with Review of Literature
}

\author{
Dr. Shweta ${ }^{1}$, Dr. Vijetha Rai ${ }^{2}$, Dr. Kuladeepa Ananda Vaidya ${ }^{3}$, \& Dr. Sukesh ${ }^{4}$ \\ ${ }^{1}$ Post graduate student, Department of Pathology, Srinivas Institute of Medical Science and \\ Research Centre, Mukka, Mangalore.575021 \\ ${ }^{2}$ Assistant professor, Department of Dermatology, Srinivas Institute of Medical Science and \\ Research Centre, Mukka, Mangalore.575021 \\ ${ }^{3}$ Associate professor, Department of Pathology, Srinivas Institute of Medical Science and \\ Research Centre, Mukka, Mangalore.575021 \\ ${ }^{4}$ Professor and HOD, Department of Pathology, Srinivas Institute of Medical Science and \\ Research Centre, Mukka, Mangalore.575021
}

\begin{abstract}
Hailey-Hailey disease (HHD), also called as familial benign chronic pemphigus, is a rare autosomal dominant blistering skin disease with waxing and waning in its clinical course. It is characterized by the presence of flaccid vesiculo-pustules, crusted erosions or expanding plaques in the areas of friction such as neck, axilla, groins, and perineum. Histopathologically shows suprabasal separations, inconspicuous dyskeratosis, acantholytic cells within the epidermis, giving a dilapidated brick wall appearance. Here we have discussed about the clinical and histopathological features of HHD and various differential diagnosis for this disease.
\end{abstract}

Keywords: Hailey-Hailey disease, Autosomal dominant, Familial benign chronic pemphigus, Skin disease.

\section{INTRODUCTION :}

Hailey-Hailey disease (HHD), also called as familial benign chronic pemphigus is a rare autosomal dominant blistering skin disease first described in 1939 by Howard and Hugh Hailey [1]. Clinically painful erosions, vesicopustules, and scaly erythematous plaques appear at sites of friction such as the sides of the neck, the axillae, and groins [2].

\section{CASE REPORT :}

A 48-year-old woman presented to dermatology outpatient department with skin lesions affecting axillae, groins and inframammary areas with a history of acute exacerbations and partial remissions since last 5 years. These lesions were pruritic and were associated with burning sensation. A positive family history was present with a similar lesion in her mother. On clinical examination, multiple warty papules, plaques with crusting seen over inframammary areas, armpit, and groin. Post inflammatory hyperpigmentation was seen. Lab investigations including a complete hemogram, liver, and renal function tests were within normal limits. Based on these findings Hailey Hailey disease and Dariers disease were included as a clinical diagnosis. Skin biopsy was taken from the lesion and sent for pathological examination in $10 \%$ formalin. Histopathological examination showed epidermal hyperplasia, hyperkeratosis, focal parakeratosis, suprabasilar clefting, inconspicuous dyskeratosis and acantholysis of keratinocytes resembling dilapidated brick wall [FIG1,2]. Underlying dermis showed sparse lymphocytic infiltrate. These microscopic features confirmed the clinical diagnosis of Hailey-Hailey disease. 


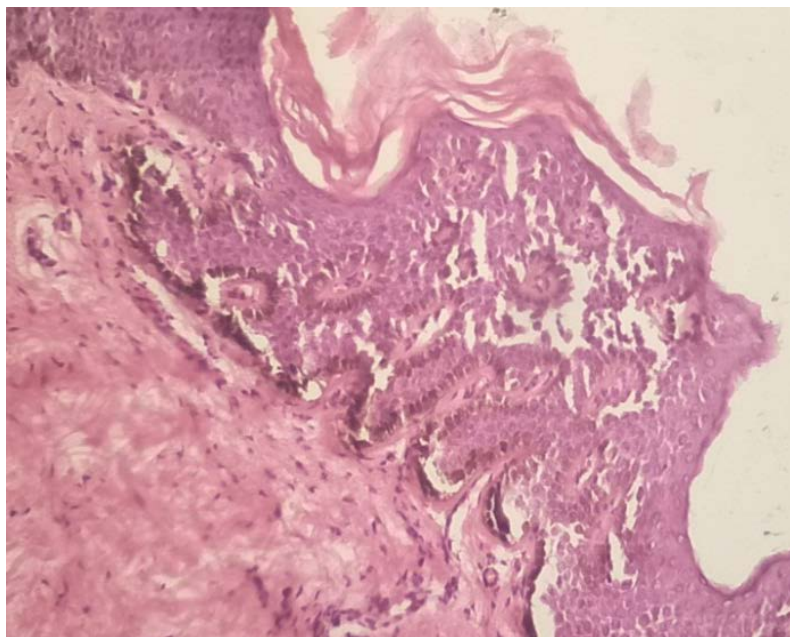

FIG 1 : Histopathology showing suprabasal clefting with acantholytic cells

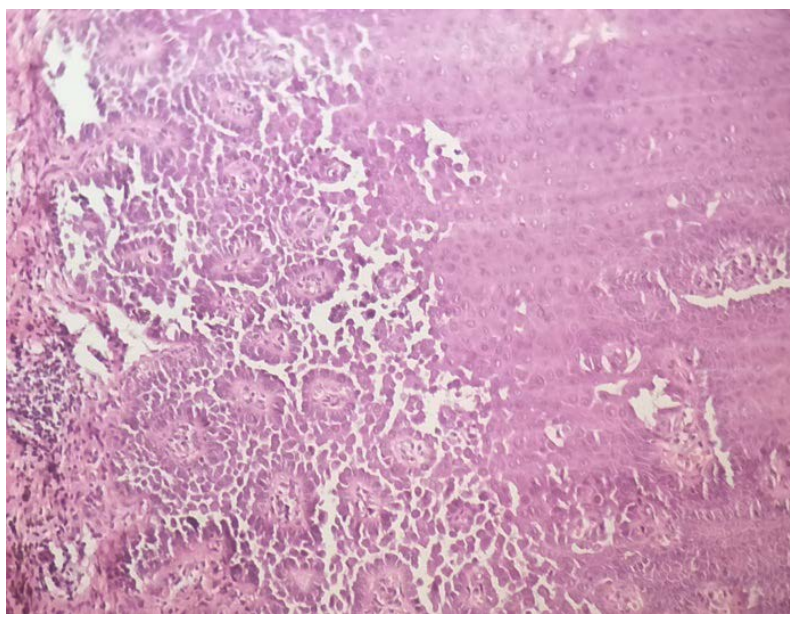

FIG. 2 : Intraepidermal acantholysis with the appearance of a "dilapidated brick wall"

\section{DISCUSSION :}

Hailey-Hailey disease is an autosomal dominant disease caused due to mutation in $\mathrm{ATP}_{2} \mathrm{C}_{1}$ gene. The gene encodes an adenosine triphosphate-powered calcium pump in the Golgi apparatus of epidermal cells $[3,4,5]$. The prevalence of this diseases around 1:50,000 [6].

The condition is clinically characterized by the presence of flaccid vesiculo-pustules, crusted erosions or plaques in the areas of friction such as neck, axilla, and groins. Flaccid lesions may be hypertrophic and malodorous with soft, flat and moist fissures [7]. In our case the lesions were warty papules and plaques with crusting and were pruritic, associated with burning sensation. This disease is usually presents around the third and fourth decades of life [2]. The clinical course of the disease is difficult to predict, but most patients experience waxing and waning severity [8] which is also noticed in our case. Colonization and secondary infections with bacterial, fungal, or viral microorganisms are known to be associated with Hailey-Hailey disease; rarely squamous cell carcinoma can also arise from these lesions [9].

Histopathological criteria for diagnosis of fully developed lesions of HHD are (a) acantholytic cells throughout or at least half the thickness of the epidermis in some foci; (b) acantholytic, dyskeratotic cells within the epidermis; (c) epidermal hyperplasia; and (d) suprabasal separations. Partial acantholysis throughout the epidermis gives rise to a dilapidated brick wall appearance $[1,10]$. In the present case acantholysis was prominent with mild dyskeratosis.

The clinical differential diagnosis of HaileyHailey disease includes intertrigo, pemphigus vulgaris, dermatophytosis, and Darier's disease [6]. Due to a low index of suspicion HHD may be some time misdiagnosed. Many a time, the disease is mistaken for intertrigo and fungal disease. In fungal diseases, active margin and satellite pustules may be present. Skin scrapings for microscopic examination and culture may be helpful to differentiate. Pemphigus vegetans is another diagnosis that may cause confusion. Crusted vegetations and pustules and oral erosions may be present in pemphigus vegetans. Darier's disease is a disease that may have similar clinical features as HHD. However, they have a different pattern of distribution. V-shaped notches of edge of nail plate, and palmar pits may be present in Darier's disease [1]. Bullous Darier's disease can mimic Hailey-Hailey disease very closely, both clinically and histopathologically. The later onset of lesions and rapid appearance and disappearance of lesions with recurrence differentiates HaileyHailey disease from bullous Darier's disease clinically. Histologically, acantholysis is more incomplete and there are fewer dyskeratotic cells in Hailey-Hailey disease as compared to bullous Darier's disease [6]. The diagnosis of vesiculo-bullous Darier's disease is difficult in view of the histological and clinical overlap with HHD. Subtle clinical and histological analysis may aid correct diagnosis and in doubt, molecular diagnosis is mandatory [11]. 
Another easily confused condition is inverse psoriasis. However, inverse psoriasis has sharper borders, fewer erosions and less crusting. Nail pitting may also be found in inverse psoriasis [1]. The pathology in some biopsies may only consist of a suprabasal slit with minimal acantholysis, and such abiopsy may be indistinguishable from that seen in pemphigus vulgaris. Yet the clinical presentation is distinctive. Some cases of Grover's disease (transient or not-sotransient acantholytic dermatosis) may share pathologic features with Hailey-Hailey disease, although dyskeratosis is more commonly seen in Grover's disease [12].

As HHD is a rare disease, the literature consists of case reports rather than well controlled studies. Thus, most of the data on treatment response are based on a small number of patients. First-line agents for treatment include topical antibiotics, topical steroids, topical antifungals and oral antibiotics. Systemic steroids, oral retinoids, methotrexate, dapsone, cyclosporin, and thalidomide are also reported to be effective [1]. Topical tacrolimus was found to be effective in the treatment of HHD [13], moreover, it is relatively safe and noninvasive [14]. Surgical approaches like surgical excision with healing by secondary intention, primary closure, grafting, dermabrasion are also been used. Erbium-YAG and $\mathrm{CO}_{2}$ laser ablation have also been reported to be effective $[1,15,16]$.

\section{CONCLUSION :}

Hailey-Hailey disease (HHD), is a rare autosomal dominant blistering skin disease. Histopathology is an important diagnostic tool to diagnose Hailey- Hailey disease, showing suprabasal separations, mild dyskeratosis, acantholytic cells within the epidermis, giving a dilapidated brick wall appearance. And in doubtful cases, molecular diagnosis is mandatory for confirmation.

\section{REFERENCES:}

[1] Cheng TS. A review on Hailey-Hailey disease. Hong Kong J. Dermatol. Venereol. 2007;15: 10-6.

[2] Yordanova I, Gospodino DV, Chavdarova V, Popovska S. Familial benign chronic pemphigus (Hailey-Hailey disease).
Bulgaria journal of IMAB - Annual Proceeding (Scientific Papers) 2007; vol. 13, book 1. DOI: 10.5272/jimab.2007131.56.

[3] de Aquino Paulo Filho T, deFreitas YK, da Nóbrega MT, Lima CB, Carriço BL, Silva MA, et al. Hailey-Hailey disease associated with herpetic eczema the value of the Tzanck smear test. Dermatol Pract Concept 2014;4:29-31.

[4] Van Beek N, Patsatsi A, Gupta Y, Möller S, Freitag M, Lemcke S, et al. A family with atypical Hailey-Hailey disease: Is there more to the underlying genetics than ATP2C1? PLoS One 2015;10:e0121253.

[5] Hu Z, Bonifas JM, Beech J, Bench G, Shigihara $\mathrm{T}$, Ogawa $\mathrm{H}$, et al. Mutations in ATP2C1, encoding a calcium pump, cause Hailey-Hailey disease. Nat Genet 2000;24:61-5.

[6] Vasudevan B, Verma R, Badwal S, Neema S, Mitra D, Sethumadhavan T. Hailey-Hailey disease with skin lesions at unusual sites and a good response to acitretin. Indian J Dermatol Venereol Leprol 2015;81:88-91.

[7] Hassan I, Keen A. Hailey Hailey disease: a case report Our Dermatol Online. 2012; 3(2): 116-8. DOI: 10.7241/ourd.20122.23.

[8] Burge S. Hailey-Hailey disease: the clinical features, response to treatment and prognosis. $\mathrm{Br} \mathrm{J}$ Dermatol. 1992;126(3):275-82.

[9] Holst VA, Fair KP, Wilson BB, Patterson JW: Squamous cell carcinoma arising in Hailey-Hailey disease. J Am Acad Dermatol. 2000;43:368-71.

[10] Michel B. "Familial benign chronic pemphigus" by Hailey and Hailey, April 1939. Commentary: Hailey- Hailey disease, familial benign chronic pemphigus. Arch Dermatol 1982; 118:774-83.

[11] Aida Khaled A et al. Bullous Darier's Disease Mimicking Hailey-Hailey Disease. Dermatol Ther. 2011; 1(2):31-5.

[12] GH Lee, et al. A Case of Eczema Herpeticum with Hailey-Hailey Disease 
Ann Dermatol;2009;21(3):311-4.

[13] Sand C, Thomsen HK. Topical tacrolimus ointment is an effective therapy for Hailey-Hailey disease. Arch Dermatol 2003;139:1401-2.

[14] Umar SA, Bhattacharjee P, Brodell RT. Treatment of Hailey-Hailey disease with tacrolimus ointment and clobetasol propionate foam. J Drugs Dermatol 2004; 3:200-3.

[15] Beier C, Kaufmann R: Efficacy of erbium-YAG laser ablation have also been reported to be effective. Arch Dermatol. 1999; 135: 423-27.

[16] Kartana M, Reitamo S: Familial benign chronicus pemphigus (Hailey Hailey disease): treatment with carbon dioxide laser vapourization. Arch Dermattol 1992; 128: 646. 